\title{
Commentary: Shunted single-ventricle neonatal ventricular-assist device support: Are we nearing a consensus strategy?
}

Nicholas D. Andersen, MD, Sonya Kirmani, MD, and Joseph W. Turek, MD, PhD

\author{
From Duke Children's Pediatric \& Congenital Heart Center, Duke Children's Hospital, Durham, NC \\ Disclosures: Authors have nothing to disclose with regard to commercial support. \\ Received for publication April 29, 2019; accepted for publication April 30, 2019. \\ Address for reprints: Nicholas D. Andersen, MD, Division of Cardiovascular and Thoracic Surgery, Duke Uni- \\ versity Medical Center, 2301 Erwin Rd, DUMC 3474, Durham, NC 27710 (E-mail: Nicholas.Andersen@ \\ Duke.edu). \\ J Thorac Cardiovasc Surg 2019;158:e71-2 \\ $0022-5223 / \$ 36.00$ \\ Copyright (c) 2019 by The American Association for Thoracic Surgery \\ https://doi.org/10.1016/j.jtcvs.2019.04.101
}

Ventricular-assist device (VAD) support for shunted singleventricle neonates represents perhaps the most challenging and unconquered frontier in pediatric mechanical circulatory support. In the current issue of the Journal, Villa and colleagues $^{1}$ describe a case of successful VAD support as a bridge to transplantation in a $2.5-\mathrm{kg}$ neonate with pulmonary atresia with intact ventricular septum (PA/IVS) and right ventricle (RV)-dependent coronary circulation. The VAD strategy employed was reminiscent of other recently reported cases $^{2-4}$ and included atrial septectomy, placement of a modified Blalock-Taussig shunt, chimney graft placement for aortic cannulation, direct right atrial venous cannulation, and connection to a continuous-flow paracorporeal device. Flow rates were driven to a cardiac index between 5 to $6 \mathrm{~L} / \mathrm{min} / \mathrm{m}^{2}$, given the need to flow to both the pulmonary and systemic circulations in parallel $(\mathrm{Qp}+\mathrm{Qs}){ }^{3}$ The strategy was successful, and the patient was supported for over 4 months before heart transplantation.

Patients with PA/IVS and RV-dependent coronary circulation represent a particularly challenging subset of neonates requiring heart transplantation, with wait-list mortality rates of approximately $50 \%$ at our institution. The phenotypes of stability can range from children who promptly arrest onto extracorporeal membrane oxygenation and suffer massive myocardial infarction from RV decompression, to those who are pseudo-stable on prostaglandins, albeit oftentimes with unsettling periods of myocardial ischemia with agitation. In the latter case, the decision to convert to VAD therapy can be difficult, particularly because RV decompression during the procedure can lead to further myocardial injury. In the present case report, the conduct of myocardial protection during the procedure was not described, and so we do not know what measures were taken to protect the myocardium during the period of atrial septectomy and RV decompression. These are incredibly important details because severe ventricular infarction during the time of VAD implant significantly complicates the postoperative

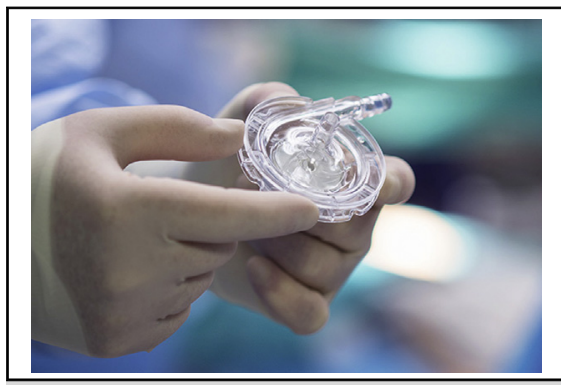

For shunted single-ventricle neonatal VAD support continuous flow may be the way to go.

Central Message

Shunted single-ventricle neonates can be successfully bridged to transplantation with use of continuous flow paracorporeal ventricularassist devices.

See Article page e67.

course and is often nonsurvivable. However, we do know that myocardial protection was achieved and likely contributed to the excellent outcome in this case, as the heart maintained good ventricular function postoperatively.

Beyond the particular nuances of PA/IVS, the key questions for shunted single-ventricle neonates are the technical details of cannulation, the VAD support strategy, and patient selection. The cannulation and VAD support strategy outlined by Villa and colleagues appears to have been embraced by many centers, as evidenced by the growing literature reports and anecdotal accounts. At our center, this has similarly become our preferred approach. The bigger question, then, is who is and isn't a candidate for VAD support? It is critically important that reports of these successes be transmitted to the pediatric heart failure community through literature reports such as these, as well as group forums such as the ACTION network (www. actionlearningnetwork.org). The present report supports the notion that any child with preserved end-organ function who is a candidate for heart transplantation should be a candidate for VAD support, as patient size, age, and anatomy have been shown not to be insurmountable barriers.

\section{References}

1. Villa CR, Lorts A, Riggs KW, Alten J, Morales DL. How small can you go? A 2.5$\mathrm{kg}$ infant with pulmonary atresia and coronary atresia bridged to cardiac 
transplantation with a paracorporeal-continuous flow ventricular assist device. J Thorac Cardiovasc Surg. 2019;158:e67-9.

2. Lal AK, Chen S, Maeda K, McCammond A, Rosenthal DN, Reinhartz O, et al. Successful bridge to transplant with a continuous flow ventricular assist device in a single ventricle patient with an aortopulmonary shunt. ASAIO J. 2014;60: $119-21$.
3. Gazit AZ, Petrucci O, Manning P, Shepard M, Baltagi S, Simpson K, et al. A novel surgical approach to mechanical circulatory support in univentricular infants. Ann Thorac Surg. 2017;104:1630-6.

4. Schmidt T, Rosenthal D, Reinhartz O, Riemer K, He F, Hsia TY, et al. Superior performance of continuous over pulsatile flow ventricular assist devices in the single ventricle circulation: a computational study. J Biomech. 2017;52:48-54. 